\title{
The treatment of nursing home-acquired pneumonia using a medically intensive Hospital in the Home service
}

$\mathrm{N}$ ursing home-acquired pneumonia (NHAP) is a common cause of admissions to hospital of people living in residential aged care facilities (RACFs); most studies have found that it accounts for the majority of non-trauma-related acute hospital admissions in this population. ${ }^{1-9}$ Dementia, immobility, swallowing problems, diabetes and renal impairment are typical comorbidities; ${ }^{9-11}$ disease severity on presentation is therefore typically greater than for community-acquired pneumonia, and in-hospital and 30-day mortality rates are high, ranging from $10 \%$ to $40 \%{ }^{4,9-15}$ NHAP requires significant inpatient resources, as the hospital length of stay for these admissions is higher than for community-acquired pneumonia, with published mean stays of between 7.0 and 18.7 days. ${ }^{9-15}$ Morbidity is also high in this group of patients, who are exposed to increased rates of unintended harm from complications such as falls and pressure wounds. ${ }^{9-17}$ MBBS, PhD, FRACGP

Man Yee Chu MRCP, FHKAM

Irani Ratnam MBBS, FRACP

Tim Spelman $\mathrm{MBBS}^{3,4}$

Karin Thursky MBBS, BSc, FRACP

1Hospital in the Home Royal Melbourne Hospital Melbourne, VIC.

2 Queen Elizabeth Hospital, Hong Kong, China.

3 Victorian Infectious Diseases Service,

Melbourne, VIC.

4 Doherty Institute fo Infection and Immunity, Melbourne, VIC.

5 NHMRC National Centre for Antimicrobial Stewardship and Guidance,

Doherty Institute fo Infection and Immunity, Melbourne, VIC

michael.montalto@ mh.org.au

doi: 10.5694/mjal5.00672

Online first $07 / 12 / 15$
Nevertheless, most NHAP patients are treated successfully and discharged back to their usual care. $7,8,18$ Despite growing concerns, most respiratory infections in this group do not involve treatment-resistant organisms. ${ }^{9-15}$

Some studies suggest that NHAP mortality does not differ between those treated in nursing homes and those transferred to hospital. ${ }^{19,20}$ However, these studies may not adequately match patients with regard to severity of disease, and it is difficult to ascertain the level of intervention delivered to NHAP patients. $^{21,22}$ Oral therapy (antibiotics, rehydration) is unlikely to be tolerated by an unwell RACF patient with pneumonia.

Families and patients accept alternatives to hospitalisation that deliver similar care to hospitals. ${ }^{23}$ Hospital in the Home (HITH)

\section{Abstract}

Objectives: To compare the outcomes for patients with nursing home-acquired pneumonia (NHAP) treated completely in a Hospital in the Home $(\mathrm{HITH})$ setting with those of patients treated in a traditional hospital ward.

Design: Case-control study.

Setting and participants: All patients admitted by the Royal Melbourne Hospital for treatment of NHAP from 1 July 2013 to 31 January 2014.

Intervention: Admission to the Royal Melbourne Hospital HITH Unit within 48 hours of presentation.

Main outcome measures: Length of stay, in-hospital and 30-day mortality, hospital readmissions (30-day), complications and unplanned returns to hospital.

Results: Sixty HITH patients and 54 hospital (control) patients were identified. Thirty-two patients (53\%) were admitted directly to HITH without any hospital or emergency stay, 25 (42\%) were referred directly from the emergency department. HITH patients were more likely to be male, older and dehydrated, and less likely to have an advanced care directive or to have had non-invasive ventilation. There were no significant differences in CURB-65 or CORB scores between the two patient groups; similar proportions were given intravenous fluids or supplemental oxygen. There were no adjusted differences in median length of stay between HITH and control patients ( -1.00 days; $95 \% \mathrm{Cl},-2.72$ to $0.72 ; P=0.252$ ) or in overall mortality at 30 days (HITH $\vee$ control patients: adjusted odds ratio [aOR], 1.97; 95\% Cl, 0.67-5.73). Inpatient mortality was lower for HITH patients (aOR, 0.19; 95\% Cl, 0.05-0.75) but unadjusted postdischarge 30-day mortality was higher (OR, 13.25; 95\% Cl 1.67-105.75).

There were no differences between the two groups with regard to complications (falls and pressure wounds) and 30-day readmission rates (aOR, 1.59; 95\% Cl, 0.30-8.53).

Conclusions: This study suggests that HITH may be an effective and safe alternative to hospital treatment for residents of aged care facilities presenting with NHAP.

has been established in Victoria for 20 years. This model of care has been shown to be safe and efficacious, including by a randomised study of mild to moderately severe community-acquired pneumonia. ${ }^{24,25}$ Its use has also been described in the acute management of older patients, and of patients in nursing homes. ${ }^{26-28}$ However, we could find no published study that specifically examined the safety and outcome of NHAP treated in a medically managed HITH care model. In July 2013, the Royal Melbourne Hospital established a mobilex-ray service that enhanced the capacity of the HITH unit to diagnose and treat patients with suspected significant lower respiratory tract infections in their nursing homes.

The aim of this study was to compare the clinical characteristics, intravenous therapy, treatment safety and outcomes of NHAP treated solely by HITH in the nursing home setting with those of conventional inhospital treatment.

\section{Methods}

\section{The Hospital in the Home intervention model}

The Royal Melbourne Hospital HITH service is responsible for all acute 
medical and pharmaceutical care, and acute nursing, pathology and radiology services for its patients, who remain inpatients of the hospital during their HITH stay. The HITH model provides a 7-day, 24-hour service, can administer oxygen and intravenous antibiotics and fluids, and includes pathology and mobile radiology services. Medical staff visit the patient in their residential home or facility each day, and one or two daily nursing visits are also made.

\section{Study population}

This study was a case-control study of patients in high-level RACFs who had been admitted to the Royal Melbourne Hospital for NHAP between 1 July 2013 and 31 January 2014. Patients who had been treated in hospital for more than 48 hours before their admission to the HITH unit were excluded. The study population included patients treated for acute lower respiratory tract infection (pneumonia, aspiration pneumonia, infective exacerbation of chronic obstructive pulmonary disease, infective exacerbation of bronchiectasis), as identified in the database of the HITH unit. The control group included patients with the same diagnoses, but admitted to hospital for conventional care during the study period; they were identified by coding and patient address data recorded by the Health Information Service of the Royal Melbourne Hospital.

\section{Data}

Data were obtained from hospital medical records, pathology and radiology systems, and the mobile $x$-ray service. Patient demographic (age, sex), comorbidity (age-adjusted Charlson comorbidity index), functional status (modified Barthel index) and Mini-Mental State Examination data (if available) were collected. Clinical features were described using the McGeer criteria, and the following laboratory data collected: white blood cell count, haematocrit, C-reactive protein, electrolyte and blood gas levels, and microbiological findings. Pneumonia severity scores (CURB-65, CORB) were calculated from clinical observations and pathology at admission. Information on antibiotic allergies, dehydration, acute confusion, intensive care unit admission, inotropic support, non-invasive ventilation, active resuscitation attempts and advanced care directives was also obtained from records for patients in both groups.

Treatment information gathered from hospital drug charts included the requirement for intravenous fluids or supplemental oxygen, and the duration of intravenous antibiotic therapy. An allergy mismatch was recorded when a patient was prescribed a drug to which an allergy had been noted in their record.

\section{Outcome measures}

The primary outcome measure was hospital length of stay. Acute length of stay refers to the stay in the acute ward or HITH; total length of stay refers to the total hospital stay, including acute care and any inhospital rehabilitation or assessment, such as geriatric evaluation and management.

Secondary outcome measures included 30-day mortality, inpatient mortality, complications, and readmission to hospital within 30 days. These data were obtained from the medical records of the hospital and the RACFs. Complications were classified as treatment-related (antibiotic drug-related adverse events, catheterrelated infections) or hospitalisationrelated (reported falls, new pressure wounds).

Unplanned interruption refers to a resumed admission to the traditional ward during the HITH admission, where such a return had not been expected or arranged for a procedure or other intervention. This is a clinical quality indicator that is routinely collected by the HITH

\section{Statistical analyses}

This study was designed a priori as an equivalence analysis. It was powered to explore the hypothesis that there was no difference between the length of stay in either direction for HITH and control patients, presuming an equivalence limit of
4.5 days. This limit was selected on the basis of published studies which suggest that the mean length of stay for traditional hospital admissions for NHAP ranges between 7.0 and 18.7 days. ${ }^{10-18}$ Using the conservative estimate of a standard deviation of 8 days, derived from the same papers and our own pilot data, it was estimated that a minimum sample size of 52 patients per group was required to attain a power of $80 \%$ for excluding a difference in mean length of stay of greater than 5 days, based on nonoverlap of two-sided confidence intervals.

Categorical variables were summarised as frequencies and percentages, and compared using $\chi^{2}$ or Fisher exact tests as appropriate. Continuous variables were summarised as means and SDs or medians and interquartile ranges (IQRs), and compared using $t$ - or Wilcoxon ranksum tests as appropriate. Length of stay data were compared using median quantile regression, fully adjusted for baseline differences. Logistic regression was used to study 30-day mortality and readmission by group, adjusted for baseline differences. Appropriate goodness-of-fit tests were conducted for regression models. ${ }^{29}$ For all analyses, $P<0.05$ was defined as statistically significant. All analyses were conducted with Stata 13 (StataCorp).

\section{Ethics approval}

Approval for the study was obtained from Royal Melbourne Hospital Ethics Committee (reference 2014050).

\section{Results}

Sixty HITH patients and 54 hospital control patients were identified during the study period. The HITH patients were older $(P=0.042)$, were less likely to have an advanced care plan at the time of treatment $(P<0.001)$, were more likely to be dehydrated $(P=0.06)$, and were less likely to have received non-invasive ventilation support $(P=0.01)$; the group included more men than women $(P=0.026)$ (Box 1$)$. There were no other significant differences in baseline characteristics between 
1 Demographic and baseline characteristics of patients in the Hospital in the Home and control groups

\begin{tabular}{|c|c|c|c|}
\hline & $\begin{array}{l}\text { Hospital in the } \\
\text { Home patients }\end{array}$ & Control patients & $P$ \\
\hline Number of patients & 60 & 54 & \\
\hline Median age (IQR), years & $86.5(83-92)$ & $84(77-98)$ & 0.042 \\
\hline Sex, male & $37(62 \%)$ & $22(41 \%)$ & 0.026 \\
\hline Antibiotic allergy & $17(28 \%)$ & $17(31 \%)$ & 0.714 \\
\hline $\begin{array}{l}\text { Median age-adjusted } \\
\text { Charlson comorbidity index } \\
\text { score (IQR) }\end{array}$ & $7(6-8.5)$ & $7(5-8)$ & 0.535 \\
\hline Advance care directives & $27(45 \%)$ & $42(78 \%)$ & $<0.001$ \\
\hline \multicolumn{4}{|l|}{ Diagnosis* } \\
\hline $\begin{array}{l}\text { Pneumonia/acute lower } \\
\text { respiratory tract infection }\end{array}$ & $50(83 \%)$ & 39 (72\%) & 0.152 \\
\hline Aspiration pneumonia & $10(17 \%)$ & $15(28 \%)$ & 0.152 \\
\hline $\begin{array}{l}\text { Chronic obstructive } \\
\text { pulmonary disease, } \\
\text { infective exacerbation }\end{array}$ & $7(12 \%)$ & $9(17 \%)$ & 0.443 \\
\hline CURB-65 score $\geq 3^{\dagger}$ & $41(68 \%)$ & $41(76 \%)$ & 0.368 \\
\hline CORB score $\geq 2^{\ddagger}$ & $36(60 \%)$ & $41(76 \%)$ & 0.070 \\
\hline Confusion & $43(72 \%)$ & $39(72 \%)$ & 0.947 \\
\hline Dehydration & $40(67 \%)$ & $22(41 \%)$ & 0.006 \\
\hline \multicolumn{4}{|l|}{ Fulfilled McGeer criteria } \\
\hline Pneumonia & $32(53 \%)$ & $30(56 \%)$ & 0.812 \\
\hline $\begin{array}{l}\text { Lower respiratory tract } \\
\text { infection }\end{array}$ & $27(45 \%)$ & $22(41 \%)$ & 0.646 \\
\hline $\begin{array}{l}\text { Pneumonia/lower } \\
\text { respiratory tract infection }\end{array}$ & 59 (98\%) & $52(96 \%)$ & 0.498 \\
\hline
\end{tabular}

the two groups. Thirty-two patients $(53 \%)$ were admitted directly into HITH care without a hospital or emergency department stay; 25 $(42 \%)$ had been referred directly from the emergency department, and three $(5 \%)$ were referred from the hospital's rapid medical assessment unit.

\section{Length of stay}

There was no difference between the median lengths of stay of HITH and control patients after adjusting for baseline differences (median regression coefficient, -1.00 days; $95 \% \mathrm{CI},-2.72$ to $0.72 ; P=0.252)$.

\section{Management of NHAP}

There was no significant difference between the proportions of patients in the two groups for whom blood tests and chest $\mathrm{x}$-rays were undertaken. Microbiological specimens were submitted for a significantly greater proportion of patients in the control group $(P<0.001)$, but there was no difference in the rate of detection of specific respiratory pathogens. Similar proportions of patients in the two groups were given intravenous fluids and supplemental oxygen. Non-invasive ventilation was more likely to be used in the control group (it was not used for HITH patients). No patient from either group was mechanically ventilated. The duration of intravenous antibiotic treatment before switching to oral antibiotics was significantly longer for HITH patients $(P<0.001)$ (Box 2).
The pattern of antibiotic prescribing is summarised in Box 3. HITH patients received ceftriaxone and moxifloxacin more often than control patients, who were more likely to receive azithromycin and metronidazole.

The frequency of antibiotic allergy mismatch in the two groups was similar. All except one of the mismatch cases involved mild or nonlife-threatening mismatches. There were no reported adverse reactions associated with antibiotic treatment.

\section{Mortality}

There were no significant differences in overall mortality at 30 days for the two groups, after adjusting for baseline differences (adjusted odds ratio [aOR] for HITH v control patients, 1.97; 95\% CI, 0.67-5.73). Inpatient mortality for HITH patients was lower (aOR, 0.19; 95\% CI, 0.05-0.75), but unadjusted postdischarge 30-day mortality was higher than for the control group (OR, 13.25; 95\% CI, 1.67-105.75). The number of deaths by 30 days after discharge (12 HITH patients, one control patient), however, limited logistic modelling to unadjusted regression, as indicated by the broad confidence interval. There were no differences between the two groups with regard to complications and 30day readmission rates after adjusting for baseline differences (aOR, 1.59; 95\% CI, 0.30-8.53) (Box 4).

One HITH patient had to return to hospital because the nursing home withdrew their consent for HITH treatment, despite the continuing consent of the family.

\section{Discussion}

This study describes the differences between the treatment of NHAP in a traditional hospital setting and when wholly managed in a medically intense HITH setting supported by a mobile x-ray service. There was evidence that the severity of the HITH cases of NHAP was similar to that of cases admitted to hospital with this condition, and our results suggest that the length of stay for these two treatment options may be comparable. It was also found that, after 
2 Investigation and management of patients with nursing home-acquired pneumonia

\begin{tabular}{lccc} 
& $\begin{array}{c}\text { Hospital in the } \\
\text { Home patients }\end{array}$ & $\begin{array}{c}\text { Control } \\
\text { patients }\end{array}$ & $P$ \\
\hline Number of patients & 60 & 54 & \\
Blood tests & $57(95 \%)$ & $53(98 \%)$ & 0.620 \\
Radiological investigations & $51(85 \%)$ & $52(96 \%)$ & 0.057 \\
$\quad$ Chest x-ray & $32(53 \%)$ & $31(57 \%)$ & 0.662 \\
$\quad$ Presence of consolidation & $25(42 \%)$ & $39(72 \%)$ & 0.001 \\
Microbiological investigations & $9(15 \%)$ & $17(32 \%)$ & 0.036 \\
$\quad$ Microbiological specimen sent & $6(10 \%)$ & $6(11 \%)$ & 0.847 \\
$\quad$ Respiratory specimen sent & $50(83 \%)$ & $40(74 \%)$ & 0.226 \\
$\quad$ Respiratory pathogens identified & $41(68 \%)$ & $44(82 \%)$ & 0.108 \\
Intravenous fluids & 0 & $6(11 \%)$ & 0.010 \\
Oxygen supplementation & $4(0-12)$ & $2(0-5)$ & $<0.001$ \\
Non-invasive ventilation support & & & \\
$\begin{array}{l}\text { Median duration (range) of } \\
\text { intravenous antibiotic treatment } \\
\text { before switch to oral treatment, days }\end{array}$ & $4(7 \%)$ & $4(7 \%)$ & 1.000 \\
Allergy mismatch & 0 & 0 & $\mathrm{NA}$ \\
Intensive care unit admission & 0 & 0 & $\mathrm{NA}$ \\
Inotropic support & 0 & 0 & $\mathrm{NA}$ \\
$\begin{array}{l}\text { Resuscitation } \\
\text { NA = not applicable. }\end{array}$ & & & \\
\hline
\end{tabular}

adjustment for baseline differences, there were no significant differences between the 30-day mortality rates and those of readmission to hospital for the two approaches. This suggests that the HITH model is effective and safe for this group of patients. The

\begin{tabular}{|c|c|c|c|}
\hline Drug & $\begin{array}{l}\text { Hospital in the } \\
\text { Home patients }\end{array}$ & $\begin{array}{l}\text { Control } \\
\text { patients }\end{array}$ & $P$ \\
\hline Ceftriaxone & $54(58 \%)$ & $41(44 \%)$ & 0.044 \\
\hline Azithromycin & $14(15 \%)$ & $23(25 \%)$ & 0.028 \\
\hline Moxifloxacin & $12(13 \%)$ & $1(1 \%)$ & 0.002 \\
\hline Metronidazole & $9(10 \%)$ & $15(16 \%)$ & 0.095 \\
\hline Benzyl-penicillin & $1(1 \%)$ & $5(5 \%)$ & 0.100 \\
\hline Gentamicin & $1(1 \%)$ & 0 & 1.000 \\
\hline Vancomycin & $1(1 \%)$ & $3(3 \%)$ & 0.343 \\
\hline Cefazolin & 0 & $1(1 \%)$ & 0.474 \\
\hline Clindamycin & 0 & $1(1 \%)$ & 0.474 \\
\hline Piperacillin/tazobactam & 0 & $2(2 \%)$ & 0.222 \\
\hline Meropenem & 0 & $1(1 \%)$ & 0.474 \\
\hline Total prescriptions & 93 & 92 & \\
\hline
\end{tabular}

shorter than expected in both groups, but the mean total hospital length of stay for the control group was within the range reported for NHAP by other studies. $^{9-15}$

There are several possible explanations for the finding that in-hospital mortality among HITH patients was lower. First, traditional hospitals may be more forceful in applying rigid limits to the duration of treatment, withdrawing active therapy earlier than in the HITH setting. Prolonging intravenous antibiotic treatment for HITH cases may improve short-term clinical responses. Second, the hospital generally provides palliation services until the death of the patient, while HITH patients were often discharged to their usual care providers after active treatment was stopped and palliation had begun. Finally, the process of transfer to hospital may accelerate clinical deterioration in this frail group.

There are potential challenges to the validity of our findings. Despite the matching of patients and adjustment for baseline differences, this was not a randomised study. We cannot, therefore, exclude the possibility that the two groups differed with regard to other variables, known or unknown, that could account for our findings. Selection of a patient into the HITH group may have been based on the awareness of HITH on the part of the attending doctor or the referring nursing home, the wishes of the patient or their family, or may have been influenced by the availability of a hospital bed at the time of presentation. The reasons for not transferring a patient to HITH in this study could include family reluctance to consider an alternative to traditional hospital care; the unwillingness of the patient's RACF to accept HITH, or a lack of awareness or will on the part of the treating emergency department doctors of HITH; further unknown or unmeasured markers of disease severity; or the time of presentation. The cluster of RACFs that allowed HITH may have influenced the outcomes (although only one facility refused ongoing HITH, and then only once). These factors may all have influenced 
4 Outcomes for patients with nursing home-acquired pneumonia

\begin{tabular}{|c|c|c|c|}
\hline & $\begin{array}{l}\text { Hospital in the } \\
\text { Home patients }\end{array}$ & Control patients & $P$ \\
\hline Number of patients & 60 & 54 & \\
\hline $\begin{array}{l}\text { Median acute care length of } \\
\text { stay (range), days }\end{array}$ & $4(1-12)$ & $4(1-28)$ & 0.959 \\
\hline $\begin{array}{l}\text { Total length of stay (range), } \\
\text { days }\end{array}$ & $4(1-12)$ & $4(1-81)$ & 0.841 \\
\hline $\begin{array}{l}\text { Mean total length of stay in } \\
\text { hospital, days }\end{array}$ & 5 & 10 & \\
\hline \multicolumn{4}{|l|}{ Complications } \\
\hline Antibiotic-related & 0 & $2(3.7 \%)$ & 0.222 \\
\hline Catheter-related & 0 & 0 & NA \\
\hline Falls & 0 & $2(3.7 \%)$ & 0.222 \\
\hline Pressure wounds & 0 & 0 & NA \\
\hline \multicolumn{4}{|l|}{ Mortality } \\
\hline Inpatient & $4(6.7 \%)$ & $17(31.5 \%)$ & 0.001 \\
\hline 30-day & $12(20 \%)$ & $1(1.9 \%)$ & 0.002 \\
\hline Overall in 30 days & $16(26.7 \%)$ & $18(33.3 \%)$ & 0.437 \\
\hline Readmission within 30 days & $6(10 \%)$ & $3(5.6 \%)$ & 0.496 \\
\hline Unplanned hospital admission & $1(1.7 \%)$ & NA & NA \\
\hline
\end{tabular}

NA $=$ not applicable.

the outcomes measured by our study, and caution is required in their interpretation.

HITH offers a partnership in which the RACF provides the sick resident with the usual supportive care, while the HITH provides acute hospitallevel intervention. A high level of care was provided: daily medical visits from doctors employed by the hospital; in most cases, twice daily visits by nurses; intravenous fluids and antibiotic treatment, blood tests and x-rays, and 24-hour cover. This study found only one episode where HITH care was terminated by the nursing home before completion, and none in which it was ended by the family. This might suggest that families and the RACFs found the intervention acceptable, but we did not specifically measure satisfaction in this study.

The global impact of NHAP is sobering: there are more than 4 million cases annually, at a median rate of 1.0-3.2 cases per 1000 bed-days and 600000 emergency admissions. ${ }^{9,11}$ In 2013, the Australian Institute of Health and Welfare found that permanent RACF patients accounted for 31760 acute hospital admissions for pneumonia in Australia during the 2008-09 financial year. ${ }^{30}$ The authors of the report assumed a mean hospital length of stay of 7 days for pneumonia, which amounts to 222320 hospital bed-days for 2008-09, or 609 fully occupied Australian hospital beds for patients with NHAP. The potential impact of moving some of those patients into HITH care would be substantial.

It is a challenge for hospitals to reconsider the best place to deliver acute care for specific segments of the population. Simply reducing hospital stays for severely unwell patients is not always acceptable. Systems are designed around traditional admission procedures, and alternatives are often not sufficiently prominent or adequately resourced to make a significant impression on the usual processes. However, the proportion of the hospital workload associated with treating RACF patients will only increase. HITH may provide a targeted and effective hospital response that can deliver equivalent quality care without extending the patient's length of stay. This requires well resourced, intensive, medically based HITH, supported by hospitallevel technologies, such as intravenous therapies, expert staff and mobile x-ray facilities, as well as the willingness to meet the challenge of switching care models for the high level of disease severity with which these patients inevitably present.

Acknowledgements: The authors acknowledge the assistance of David Dunt in the preparation of this article.

Competing interests: No relevant disclosures.

(c) 2015 AMPCo Pty Ltd. Produced with Elsevier B.V. All rights reserved. 
1 Graverholt B, Riise T, Jamtvedt G, et al. Acute hospital admissions among nursing home residents: a population based observational study. BMC Health Serv Res 2011; 11: 126.

2 Quinn T. Emergency hospital admissions from care homes: who, why and what happens? A cross sectional study. Gerontology 2011; 57: 115-120.

3 Godden S, Pollock AM. The use of acute hospital services by elderly residents of nursing and residential care homes. Health Soc Care Community 2001; 9: 367-374.

4 Hillen J, Reed R, Woodman RJ, et al. Hospital admissions from aged care facilities to a major public hospital in South Australia. Australas J Ageing 2011; 30: 202-207.

5 Finuncane $\mathrm{P}$ Wundke $\mathrm{R}$, Whitehead $\mathrm{C}$, et al. Use of inpatient hospital beds by people living in residential care. Gerontology 2000; 46: 133-138.

6 Harris J, Finuncane P, Healy D, Bakarich A. Use of inpatient services by people aged 90-99 years. Med J Aust 1997; 167: 417-420. https://www. mja.com.au/journal/1997/167/8/useinpatient-hospital-services-peopleaged-90-99-years

7 Finn J, Flicker L, Mackenzie E, et al. Interface between residential aged care facilities and a teaching hospital emergency department in Western Australia. Med J Aust 2006; 184: 432-435. https://www.mja.com.au/ journal/2006/184/9/interfacebetween-residential-aged-carefacilities-and-teaching-hospital

8 Ingarfield S, Finn J, Jacobs I, et al. Use of emergency departments by older people from residential care: a population based study. Age Ageing 2009; 38: 314-318.

9 Liapikou A, Polverino E, Cilloniz C, et al; Community-Acquired Pneumonia Organization (CAPO) Investigators. A worldwide perspective of nursing home-acquired pneumonia compared with community-acquired pneumonia. Respir Care 2014; 59: 1078-1085.

10 Ewig S, Klapdor B, Pletz M, et al: CAPNETZ study group. Nursing-homeacquired pneumonia in Germany: an 8-year prospective multicentre study. Thorax 2012; 67: 132-138.
1 El-Solh AA, Niederman MS, Drinka P. Nursing home-acquired pneumonia: a review of risk factors and therapeutic approaches. Curr Med Res Opin 2010; 26: 2707-2714.

12 Venditti M, Falcone M, Corrao S, et al Study Group of the Italian Society of Internal Medicine. Outcomes of patients hospitalized with communityacquired healthcare-associated and hospital acquired pneumonia. Ann Intern Med 2009; 150: 19-26.

13 Fukuyama H, Yamashiro S, Tamaki H, Kishaba T. A prospective comparison of nursing- and healthcare-associated pneumonia (NHCAP) with communityacquired pneumonia (CAP). J Infect Chemother 2013; 19: 719-726.

14 Lee JH, Kim YH. Comparison of clinical characteristics between healthcareassociated pneumonia and communityacquired pneumonia in patients admitted to secondary hospitals. Braz J Infect Dis 2012; 16: 321-328.

15 Meehan TP, Chua Reyes JM, Tate J, et al. Process of care performance, patient characteristics and outcomes in elderly patients hospitalized with community-acquired or nursing homeacquired pneumonia. Chest 2000; 117: 1378-1385.

16 Broockvar K, Gruber-Baldini A, Burton $L$, et al. Outcomes of infection in nursing home residents with and without early hospital transfer. J Am Geriatr Soc 2005; 53: 590-596.

17 Fried T, Gillick M, Lipsitz L. Short-term functional outcomes of long-term care residents with pneumonia treated with and without hospital transfer. J Am Geriatr Soc 1997; 45: 302-307.

18 Quinn T. Emergency hospital admissions from care homes: who, why and what happens? A cross sectional study. Gerontology 2011; 57: 115-120.

19 Loeb M, Caruscone S, Goeree R, et al. Effect of a clinical pathway to reduce hospitalisations in nursing home residents with pneumonia: a randomized clinical trial. JAMA 2006; 295: 2503-2510.

20 Mylotte J. Reducing hospitalizations in nursing home patients with pneumonia. JAMA 2006; 296: 2206-2207.
21 Walsh E, Winer J, Haber S, et al. Potentially avoidable hospitalisations of dually eligible Medicare and Medicaid beneficiaries from nursing home and Home- and CommunityBased Services waiver programs. J Am Geriatr Soc 2012; 60: 821-829.

22 Ouslander J. Reducing unnecessary hospitalisations of nursing home residents. $N$ Engl J Med 2011; 365: 1165-1167.

23 Caruscone S, Loeb M, Lohfeld L. Pneumonia care and nursing home: a qualitative descriptive study of resident and family preferences. BMC Geriatrics 2006; 6: 2.

24 Montalto M. How safe is hospitalin-the-home care? Med J Aust 1998; 168: 277-280.

25 Richards DA, Toop LJ, Epton MJ, et al. Home management of mild to moderately severe community-acquired pneumonia: a randomised controlled trial. Med J Aust 2005; 183: 235-238. https://www.mja.com.au/journal/2 005/183/5/home-management-mildmoderately-severe-communityacquired-pneumonia-randomised

26 Leff B, Burton L, Mader SL, et al. Hospital in the Home: feasibility and outcomes of a program to provide hospital level care at home for acutely ill older patients. Ann Intern Med 2005; 143: $798-808$

27 Montalto M, Lui B, Mullins A, Woodmason K. Medically-managed Hospital in the Home: 7 year study of mortality and unplanned interruption. Aust Health Rev 2010; 34: 269-275.

28 Montalto M. Hospital in the nursing home. Treating acute hospital problems in nursing home residents using a Hospital in the Home model. Aust Fam Physician 2001; 30: 1010-1012.

29 He X, Zhu LX. A lack-of-fit test for quantile regression. J Am Statist Assoc 2003; 98: 1013-1022.

30 Australian Institute of Health and Welfare. Movement between hospital and residential aged care 2008-09. (Cat. No. CSI 16; Data linkage series no. 16.) Canberra: AlHW, 2013. http://www. aihw.gov.au/WorkArea/Download Asset.aspx?id $=60129544618$ (accessed Sep 2015). 